\title{
Uma perspectiva socioambiental sob o foco da Arte e da Lei com Teatro do Oprimido e grupo Marias do Brasil
}

Una perspectiva socioambiental a la luz del arte y de la ley. El teatro del oprimido y el grupo Marías de Brasil

\section{A Socio-Environmental Perspective under the Light of Art and Law. The Theater of the Oppressed and the Marias do Brasil Group}

Claudete Felix De Sousa aclaudetefelix@gmail.com

\section{Resumo}

Praticado nos cinco continentes, o método do Teatro do Oprimido foi sistematizado como vigoroso instrumento dialógico com a sociedade. $\mathrm{O}$ teatrólogo Augusto Boal, iniciou a criação deste método nos anos 60, durante o período de ditadura militar no Brasil e fundou

o Centro de Teatro do Oprimido, no Rio de Janeiro, em 1986, com sua equipe (da qual faço parte desde essa época), formando centenas de grupos populares. Marias do Brasil é um grupo formado por trabalhadoras domésticas, migrantes de regiões áridas do pais, com baixo nível de escolarização. Jogos, exercícios e técnicas especificas, possibilitaram que as atrizes montassem seus próprios espetáculos a partir de suas reais histórias de vida, inclusive músicas e poemas. As integrantes apresentaram em praças e teatros suas opressões sociais e discutiram diretamente com a população seus direitos trabalhistas e as mudanças urgentes na legislação brasileira. A técnica utilizada 
denomina-se Teatro-Forum onde cria-se um processo interativo com a plateia que, após assistir ao espetáculo, é convidada a substituir o personagem oprimido para mostrar alternativas contra às opressões vividas em cena. O resultado é o extenso apoio às mulheres migrantes e aos sindicatos, mais o fortalecimento das ações sociais dando maior visibilidade aos conflitos da categoria na busca de soluções trazidas pela legislação vigente. Trata-se de uma experiencia única, desde 1998, no Centro de Teatro do Oprimido, com o Teatro Legislativo, uma das vertentes do método, onde a Arte e a Lei potencializam a transformação social.

Palavras chave: teatro do oprimido; legislação; trabalhadoras domésticas.

\section{Resumen}

Practicado en los cinco continentes, el método del teatro del oprimido se sistematizó como un sólido instrumento de diálogo con la sociedad. El teatrólogo Augusto Boal inició la creación de este método en los años 1960, durante la dictadura en Brasil, y fundó el Centro de Teatro del Oprimido en Río de Janeiro, en 1986, con su equipo (del que hace parte desde entonces), y formó centenares de grupos populares. Marías de Brasil es un grupo formado por trabajadoras domésticas, migrantes de regiones áridas del país, con bajo nivel de escolaridad. Juegos, ejercicios y técnicas específicas permitieron que las actrices montaran sus propios espectáculos a partir de sus historias reales de vida, incluyendo música y poemas. Las integrantes presentaron en plazas y teatros sus opresiones sociales y discutieron directamente con la población sus derechos laborales y los cambios urgentes en la legislación brasileña. La técnica utilizada se llama teatro-foro en el que se establece un proceso interactivo con la audiencia que, después de asistir al espectáculo, es invitada a sustituir el personaje oprimido para proponer alternativas contra las opresiones vividas en el escenario. El resultado es un amplio apoyo a las mujeres migrantes y a los sindicatos, el fortalecimiento de las acciones sociales, lo que da una mayor visibilidad a los conflictos de la categoría en la búsqueda de soluciones aportadas por la legislación vigente. Se trata de una experiencia única, desde 1998, en el Centro de Teatro del Oprimido, con el teatro legislativo, una de las vertientes del método, donde el arte y la ley potencian la transformación social.

Palabras clave: teatro del oprimido; legislación; trabajadoras domésticas. 


\begin{abstract}
The Theater of the Oppressed method is practiced in the five continents, and it was systematized as a vigorous instrument for dialogue with the society. The Brazilian playwriter Augusto Boal created this method in the 1960s, during the military dictatorship period, and founded the Center for Theater of the Oppressed, in Rio de Janeiro, in 1968, with his team; since then, he has been part of this team, and has created hundreds of popular groups. Marias do Brasil is a group formed by domestic workers, coming from arid regions of the country, with low level of schooling. Games, exercises, and specific techniques enable the actresses to stage their own shows based on their real stories of life, including music and poems. The members of the group performed in places and theaters where they presented their social oppressions, and directly discussed with the population their labor rights and the urgent changes to be made to the Brazilian legislation. The technique used is called theater-forum where an interactive process with the audience is initiated. The audience, after watching the spectacle, is invited to replace the oppressed character to propose alternatives against the oppression experienced in the scene. The result is the extensive support for migrant women and labor unions, and the strengthening of social actions, giving greater visibility to the conflicts of the category in the search for solutions brought by current legislation. It is a unique experience, since 1998, in the Center of Theater of the Oppressed, with the legislative theater, one of the aspects of the method, where the art and the law make the social transformation possible.
\end{abstract}

Keywords: Theater of the Oppressed; legislation; domestic workers.

\title{
Um recorte social e geográfico do nordeste brasileiro
}

O Brasil é um país de proporção continental, na extensão de seus quase dez milhões de quilômetros quadrados, formado de climas extremos com realidades geográficas e sociais distintas e injustas. A região nordeste do país se alastra por uma área de 1.554.291,6 $\mathrm{km}^{2}$ (corresponde a 18,2\% do território nacional com 57, 36 milhões de habitantes (estimativa 2017 - IBGE), sendo a mais castigada pela escassez de chuvas e péssimas condições de sobrevivência da população nordestina. A dimensão social agoniza diante da dimensão ambiental.

Desde a colonização protagonizada pela invasão dos portugueses, no início do século XVI, esta região do país sofreu grandes transformações ambientais, sendo vítima de extrativismo abusivo de minérios e do uso excessivo do solo para as plantações, 
principalmente de cana de açucar, com grande queima de madeira para o funcionamento dos engenhos e na construção de imensos latifúndios. A população nordestina, após os habitantes indígenas serem trucidados em ampla escala pelos colonizadores, foi constituída de trabalhadores brancos, portugueses em sua maioria, vindos da colonia, para usufruir e produzir benefícios à coroa lusitana, e de escravos negros (homens, mulheres e crianças) capturados e trazidos à força da África para servirem como mão de obra das propriedades rurais. Cidades e povoados, estradas e portos foram instalados para aumentar a atividade açucareira entre Brasil e Portugal. Assim, se inicia o processo demográfico desta região, pelo litoral até o interior da região.

Uma reflexão sobre o tema nos remete ao quadro extremo de desigualdades sociais presentes no país, sinalizando uma estrutura fundiária instituída por tomada de posse das terras de maneira injusta no século XVI, entre os segmentos sociais, que se perpetuam até os dias atuais. $\mathrm{O}$ setor latifundiário/escravagista inaugura uma marca histórica como consequência negativa para o desenvolvimento da nação. Um cenário de conflitos entre aqueles que detêm o acesso e o poder sobre a terra e aqueles que, destituídos deste direito, estão sujeitos a relações de trabalho como seres subalternos, sem benefícios ou direitos legais sobre a profissão que exercem em propriedades com atividades de agricultura e pecuária (Freyre, 1977).

No século XX, décadas de 50 e 80, o processo migratório da população nordestina foi intenso rumo às áreas de maior industrialização situadas na região sudeste, como São Paulo e Rio de Janeiro: grandes polos de atração para milhões de pessoas em busca de trabalho e melhores condições de sobrevivência. Os homens apresentavam-se para trabalhar na construção civil e as mulheres, como trabalhadoras domésticas em casas de família. Nesta época, o aumento excessivo da população fez com que a região sudeste sofresse grande impacto em seu processo de urbanização ao receber novos habitantes.

Os trabalhadores rurais ainda não têm os direitos legais que trabalhadores de outras áreas, sofrendo discriminação sem vínculo empregatício, marcando os conflitos sociais e a luta pela reforma agrária nos dias atuais. O Movimento dos Trabalhadores Rurais sem Terra - MST - se torna oficial no início da década de 80 , fortalecendo a luta de pequenos agricultores, posseiros, pessoas atingidas por barragens, pela justa distribuição de terras ociosas ou ilegalmente ocupadas. Assim também discriminada é a classe das trabalhadoras domésticas. Estas são as duas categorias trabalhistas cuja legislação está aquém do patamar da cidadania brasileira, ainda em 2016. 
Neste território nordestino atualmente encontra-se a Caatinga (do tupi: $k a^{\prime} a$ [mata $]+$ tinga $[$ branca $]=$ mata branca) que é o único bioma exclusivamente brasileiro e grande parte do seu patrimônio biológico não pode ser encontrado em nenhum outro lugar do planeta. Este nome decorre da paisagem esbranquiçada apresentada pela vegetação durante o período da seca: a maioria das plantas perde as folhas e os troncos tornam-se secos e esbranquiçados. O uso insustentável de seus solos e recursos naturais ao longo de centenas de anos de ocupação, associado à imagem de local pobre e seco, transformaram a caatinga bastante degradada pela ação humana. Abaixo imagem da cidade onde nasceu Maria José, atriz do grupo. Nesta paisagem, ela cresceu e, assim que teve oportunidade, partiu para o Rio de Janeiro.
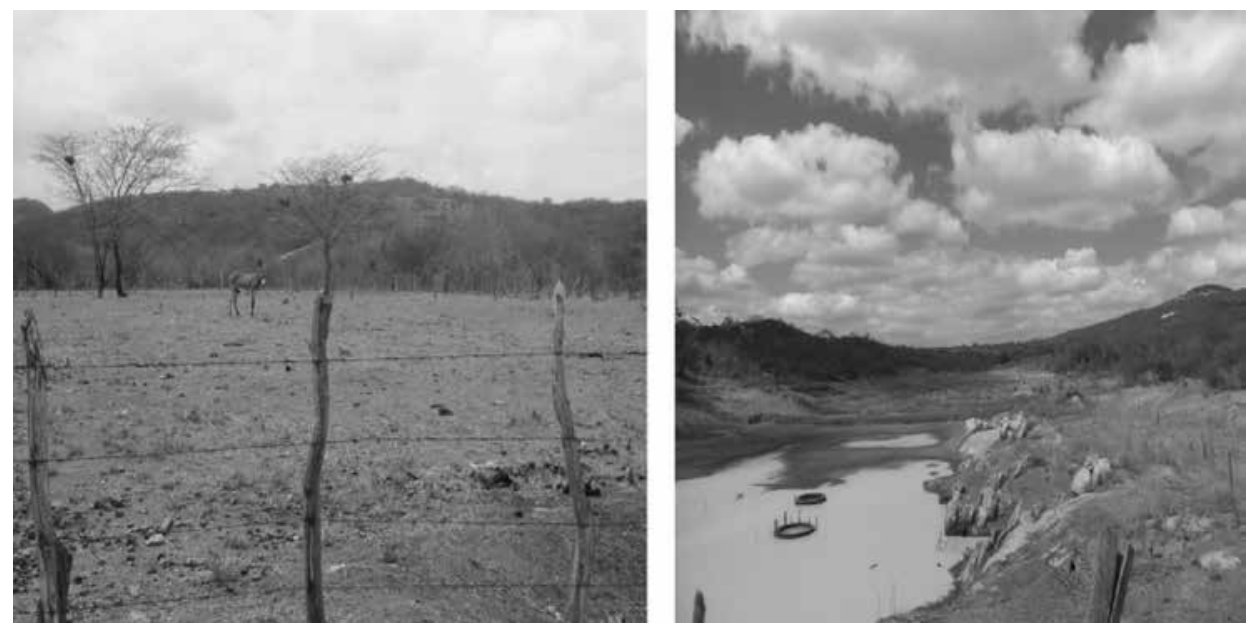

Figuras 1 e 2. Sertão da Paraíba, dois anos sem chuva.

Fonte: fotografia tirada pela autora.

\section{Histórico e início do trabalho doméstico no Brasil}

O período de escravidão deu origem à profissão das trabalhadoras domésticas, deixando sangrentas marcas no desenvolvimento demográfico desde o período colonial brasileiro. Em 13 de maio de 1888 foi assinada a Lei Áurea que extinguia a exploração da mão-de-obra escrava no Brasil para homens e mulheres. No entanto, os escravos libertos não tinham lugar para onde ir, nem o que cultivar para sobreviver. A atividade doméstica é oferecida às meninas e às moças solteiras, pobres e analfabetas; também pela tenra idade, eram pessoas completamente 
desqualificadas para o mercado de trabalho, ou seja, não tinham capacidade para serem inseridas em atividades como indústria e comércio. Dessa forma, em busca de subsistência, trabalhavam em casas de família, recebendo em troca dos serviços prestados, alimentação, vestuário, moradia e pequenos valores. Deste modo, o trabalho doméstico - extremamente necessário - continuou a ser exercido majoritariamente por mulheres negras, jovens e inclusive crianças.

O valor social do trabalho doméstico é de enorme mérito ao desenvolvimento da economia nacional. Entretanto, até os dias de hoje, é considerada uma atividade sem importância e que não gera lucro para o patrão. Diante desse ponto de vista, permeado por preconceitos, machismo e racismo, sempre houve evidente desqualificação desta categoria. E nesse rastro de exploração humana, as mulheres foram submetidas a condições degradantes no desempenho de suas atividades, sem a proteção das leis trabalhistas como os demais profissionais. Com o fim da escravidão, aqueles que trabalhavam em casas de família, receberam nova denominação: de escravo para empregado doméstico (Giacomini, 1988).

Segundo dados da Federação Nacional das Trabalhadoras Domésticas - FENATRAD- (http://www.fenatrad.org.br/site/) no Brasil há dez milhões de trabalhadores (as) domésticos (as) onde $96 \%$ são mulheres: em sua maioria negras, oriundas das camadas mais pobres de nossa sociedade. Cerca de $2 / 3$ dos empregadores ainda não seguem as leis estabelecidas para o trabalho doméstico remunerado. Há nesta categoria uma assimilação das mulheres de baixa escolaridade e sem experiência profissional no mercado de trabalho. Além disso, funciona como a porta de entrada para jovens migrantes: da pobreza da zona rural seguem para o "luxo" industrial das grandes capitais do país.

O quadro existente nos dias atuais avançou em muitos pontos, não há dúvida. Mas a realidade na prática do dia a dia do serviço dentro das casas de família gira em torno de como enfrentar e argumentar com seus patrões, pessoas mais ricas e cultas, se muitas empregadas não conhecem a lei que as protege. E, se têm maior compreensão dos seus direitos, entretanto, na hora da negociação com patronato, entre quatro paredes - da casa que não é dela -, a voz se enfraquece e ela se submete. O Sindicato dos Trabalhadores Domésticos ganha cada vez mais força e espaço entre a mídia, as redes socias e a população em geral, revelando a luta constante para que a lei seja revista e alterada em benefício das classes trabalhadoras mais oprimidas. 


\section{A origem de Maria: sertão árido da Paraíba}

No sertão árido do Estado da Paraíba, no berço da caatinga, nasceu Maria José, hoje com 68 anos. Ela traz em si a força da mulher nordestina acostumada desde criança a andar quilômetros de pés descalços para trabalhar na roça e carregar preciosa água do açude à porta de casa. Maria José foi mais distante até chegar ao Rio de Janeiro, num período de intensa migração, em busca de melhores condições de trabalho. O salário baixo somente lhe permite habitar em moradias muitos pobres das comunidades cariocas (favelas).

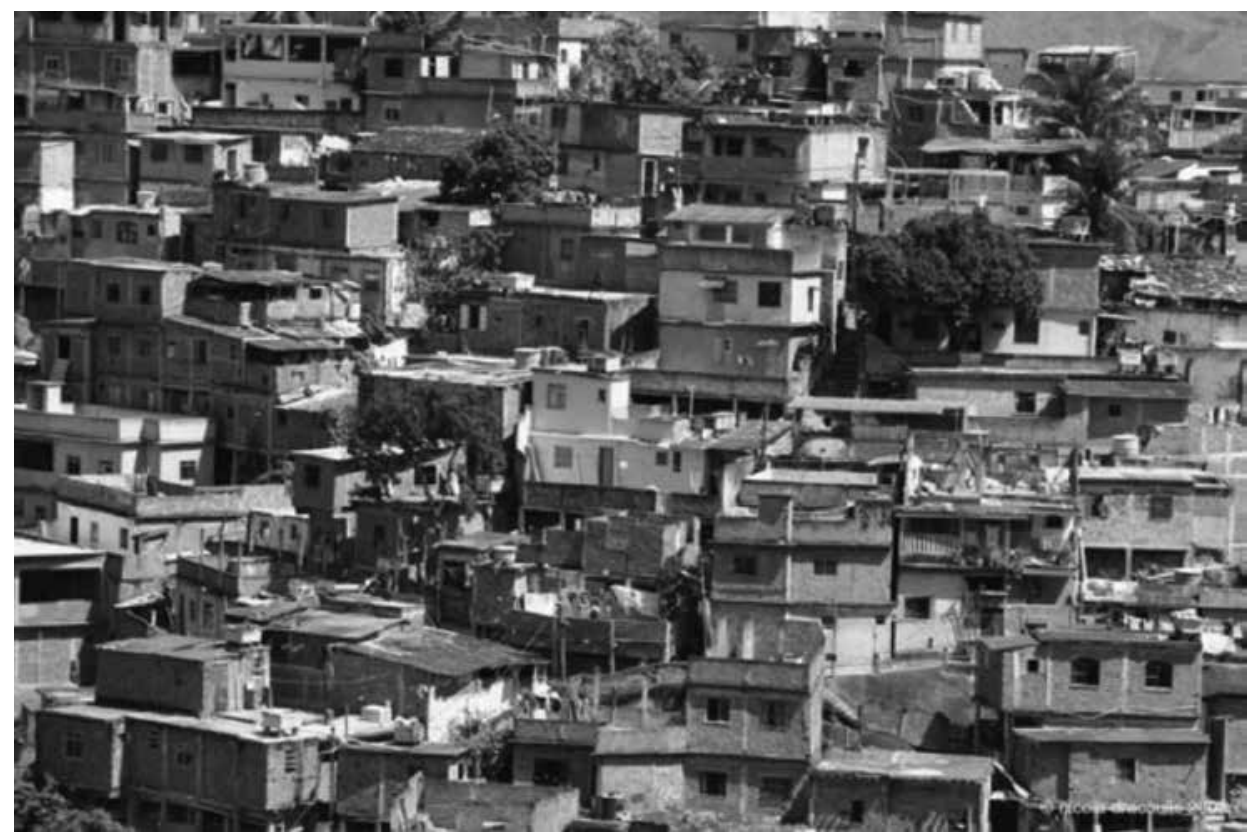

Figura 3. Local de moradia da população desfavorecida no Rio de Janeiro. Complexo do Alemão, conjunto de 13 favelas compopulação em torno de 70.000 habitantes.

Fonte: http://vozdacomunidade.s3.amazonaws.com/wp-content/uploads/2016/05/ historiadocomplexo.jpg

Depois de quase duas décadas como atriz e fazendo parte da diretoria do Sindicato das Trabalhadoras Domésticas do Rio de Janeiro, Maria José fala da sua experiencia como atriz: "Aprendi a dizer "não" com o Teatro do Oprimido de diversas maneiras. A vida da trabalhadora doméstica é muito dura, cheia de humilhações. 
Fugi da seca da Paraíba, deixei a casa e a minha família para tentar a sorte grande na Cidade Maravilhosa, ainda mocinha. Muitas vezes aceitava trabalhar num palacete apenas em troca de um chão pra dormir e um pouco de comida. Fui muito explorada, porque sempre tive muito medo. Mas precisava mandar dinheiro pra minha mãe e meus irmãos menores. Trabalhava até de madrugada, sem parar, todos os finais de semana, não tinha férias, minhas mãos calejadas e minhas pernas cansadas doíam no final do dia. Aceitava as ordens dos patrões de cabeça baixa, por mais que fossem humilhantes... eu precisava comer, então aprendi a sempre dizer "sim". Aos 44 anos consegui aprender a ler e escrever já no Rio de Janeiro. Na mesma escola me tornei atriz, quando em 1998, o pessoal do Centro de Teatro do Oprimido (CTO) foi se apresentar e convidou quem quisesse a formar um grupo teatral. Eu era tímida, mas aceitei, porque achava teatro a coisa mais linda, via na televisão... Então fizemos jogos, exercicios, técnicas do Teatro do Oprimido: contamos nossas histórias de vida e fizemos a peça "Quando o verde dos teus olhos, se espalhar na plantação." A estreia neste mesmo ano, no Parque do Flamengo, entre as copas das árvores e as areias da praia. Assim comecei a conhecer um outro mundo, a falar mais alto, ser ouvida por muita gente e entender melhor meus direitos e as leis da minha profissão. Desde então, estou em cena, nos palcos dos teatros, nas ruas e nas comunidades. Meus patrões foram me aplaudir no Teatro. Agora, ou eles me respeitam ou vou embora sem medo, pois, além de conhecer meus direitos, sei argumentar como igual, sei agir e lutar pelas conquistas da minha categoria. Nós - Marias do Brasil - compreendemos e praticamos diversas alternativas possíveis contra as opressões mostradas em nossos espetáculos: a falta de carteira assinada, excesso de horas extras, o abuso dos patrões e o assédio sexual sofrido nas casas em que trabalhamos. Viajamos pelo Brasil com o Teatro do Oprimido, entregamos nas mãos do vice-presidente da Câmara dos Deputados em Brasília o abaixo assinado que nós, atrizes do grupo Marias do Brasil, juntamente com o Sindicato das Trabalhadoras Domésticas do Rio de Janeiro, organizamos e recolhemos milhares de assinaturas pela igualdade dos direitos trabalhistas da categoria, participei do Forum Social Mundial (minha mente ficou mais clara, tanta gente, tantas ideias, de tanto lugar). Assim, nesse caminho sem volta, continuei seguindo em frente e nunca mais quis parar". 


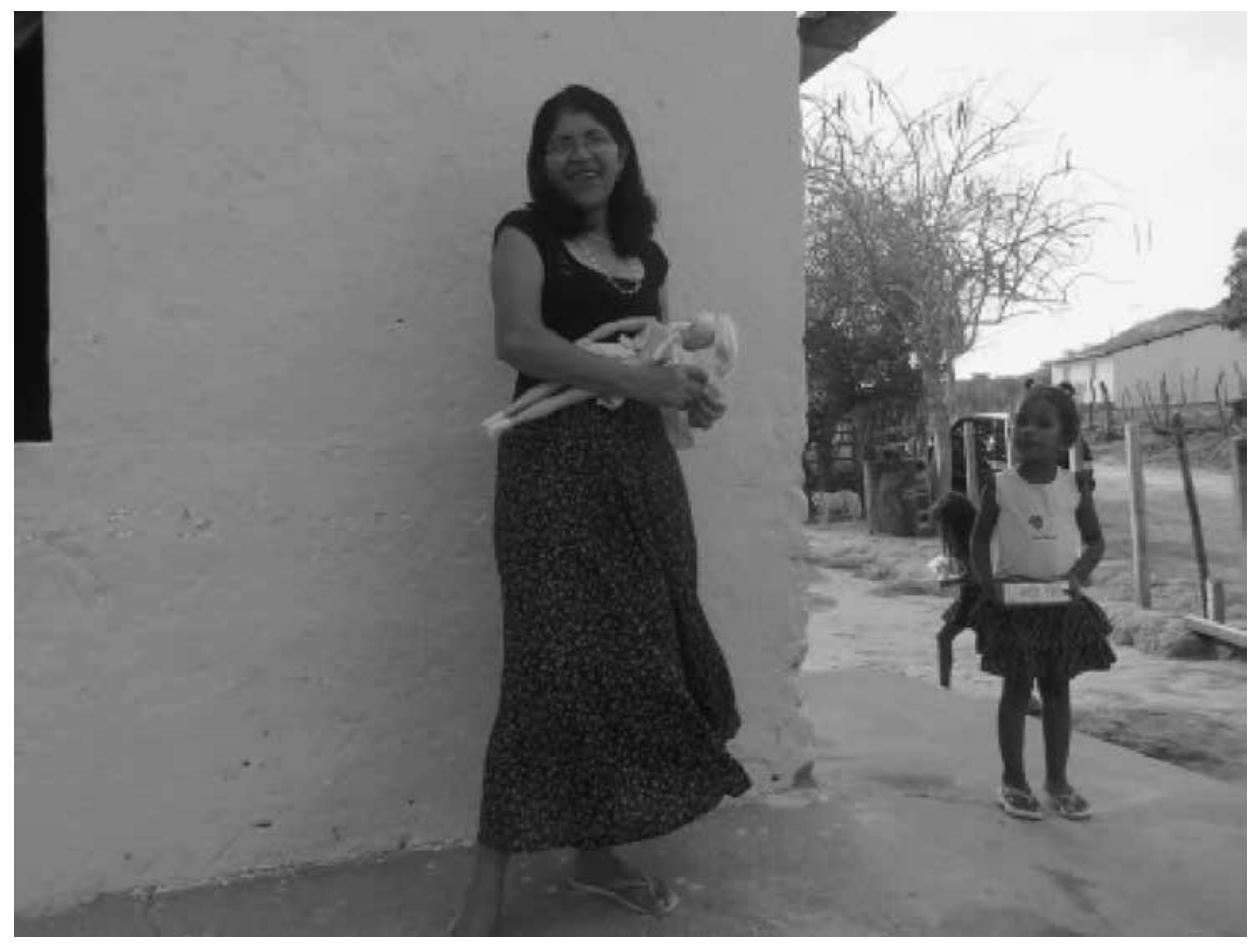

Figura 4. Maria José na sua cidade natal, a seca ainda é o maior problema.

Fonte: fotografia tirada pela autora.

\section{A história e a aplicabilidade do método do Teatro do Oprimido}

Este trabalho escrito, aqui apresentado, tem um percurso de 30 anos com teoria e prática diretamente ligado à criação e à sistematização do método do Teatro do Oprimido, com a direção de Augusto Boal, durante 23 anos, e a fundação do Centro de Teatro do Oprimido (CTO). Fundado em 1986, o CTO formou centenas de grupos populares em diversas cidades em todo o Brasil. Muito do que está aqui registrado eu vivenciei, vi e ouvi das integrantes do grupo Marias do Brasil: visitei suas casas e conheci suas famílias durante 19 anos em que me disponibilizei como diretora artistica deste grupo.

A prática do Teatro do Oprimido provoca e consolida grandes transformações individuais e sociais. Teatro Forum é a técnica interativa usada onde a plateia, após assistir ao espetáculo, é convidada a substituir o personagem oprimido para criar alternativas contra as opressões vividas em cena. O resultado é a divulgação e 
apoio às migrantes e aos sindicatos mais o fortalecimento das ações sociais dando maior visibilidade aos conflitos. Oficinas com jogos e técnicas levam à reflexão e à desmecanização do corpo também são oferecidas às comunidades.

Para o teatrólogo brasileiro Augusto Boal, a linguagem teatral é essencialmente expressa como linguagem humana, num espaço de exposição da vida cotidiana aberta a todas as transgressões permitidas em cena. A sistematização do método do Teatro do Oprimido baseia-se na formação de grupos populares, oficinas abertas ao público e criação e montagem de espetáculos com a interatividade do público nas cenas. O princípio básico do método é a transformação social através da desmecanização física e mental e da acessibilidade à compreensão e discussão da legislação em todas as áreas necessárias.

Dominar os meios de produção artística é a meta para formação de multiplicadores em Teatro do Oprimido. Para tanto, a organização desta metodologia tem base nos jogos (diálogos corporais), exercícios (monólogos corporais) e técnicas de imagem e de ensaio. $\mathrm{O}$ arsenal do Teatro do Oprimido compreende as seguintes modalidades de processo criativo e colaborativo:

- Arco íris do desejo (técnicas diversificadas para montagem de cenas com conflitos interpessoais e opressões internalizadas);

- Teatro Jornal (nove diferentes modalidades de interpretar as notícias de jornais);

- Teatro Invisível (a cena é realizada no local onde acontece o conflito e mostrada ao público, no entorno, que, desconhecendo ser uma montagem teatral, participa de maneira espontânea);

- Teatro Legislativo (cenas de Teatro Forum apresentadas ao público que compreende, cria, discute e vota encaminhamentos legislativos sobre os temas abordados nos espetáculos).

As técnicas de Teatro Imagem despertam e consolidam debates sobre os temas levantados das cenas criadas pelos integrantes dos grupos - em movimento ou estáticas - e suscitadas por sons, imagens ou palavras. Nesse processo, as pessoas estão aptas a contarem histórias de suas vidas a partir do ponto de vista do oprimido (aquele que luta para realizar seu desejo). O conflito entre protagonista que luta e o antagonista que se opõe à essa luta deve ser claro, objetivo e urgente: o Teatro Forum nasce do embrião de uma história cuja pergunta instigue o público, 
pois na segunda parte do espetáculo quem entra em cena é o espectador instigado pelos conflitos apresentados. O diálogo teatral que se instaura vem através da alternativa que o espectador leva ao antagonista e aos possíveis aliados.

Todo o jogo é dinamizado pelo curinga (que facilita e provoca o diálogo em ação teatral entre ator e público).

\section{Início do grupo Marias do Brasil}

Dentre muitas experiências e projetos do CTO, Augusto Boal assume o cargo de vereador na Câmara Municipal do Rio de Janeiro de 1993 a 1996; nossa vivência e práticas nas ruas da cidade aprimoram o mandato político teatral com toda estrutura o que se transformou no projeto Teatro Legislativo. Principalmente escolas públicas e comunidades foram visitadas pela vereança de Boal com espetáculos, oficinas e formação de grupos populares (cerca de 60 foram criados durante os 4 anos). Crianças, jovens adultos e idosos fizeram jogos e exercícios, praticaram as técnicas e se apresentaram em hospitais, igrejas, praias e teatros por todos os bairros, para, através da arte, estimular a discussão e a compreensão dos encaminhamentos legislativos.

Depois que terminou o mandato, o desafio era continuar com o Teatro Legislativo com os grupos populares. Em 1998, inicia-se a formação de um novo grupo de Teatro do Oprimido com trabalhadoras domésticas do Rio de Janeiro: alcança-se com este grupo um longo processo de construção coletiva baseada na metodologia do Teatro do Oprimido e amplia-se um grande caminho de experiencias inovadoras no processo do Teatro Legislativo. Os encontros iniciais aconteceram em escola pública com curso noturno para alfabetização de adultos. As histórias de opressão entre as trabalhadoras e seus patrões são muito semelhantes entre si: a jovem que sai de casa, a seca da região onde vive, a miséria, a falta de perspectivas para sobreviver e arrumar emprego; à procura de melhores condições de sobrevivência, o caminho segue até o Rio de Janeiro, onde, para o migrante, existe maior abundância de empregos e de chuvas constantes. Ouvindo o que o grupo relatava sobre suas trajetórias saindo da cidade natal, devido à miséria e às péssimas condições de sobrevivência, uma das integrantes dizia: "Não saio mais do Rio de Janeiro, aqui o lixo é melhor que na minha terra, lá no sertão, a miséria era tanta que nem lixo sobrava porque a gente comia tudo e não sobrava nada"!

Marias do Brasil: mulheres, estudantes, trabalhadoras domésticas, migrantes da região nordeste do Brasil, atrizes amantes da arte, quase todas 
chamavam-se Maria (Maria José, Maria da Conceição, Maria Izabel, Maria de Fátima, Maria Aparecida, Maria Vilma). Nasce, assim, o grupo de Teatro do Oprimido Marias do Brasil.

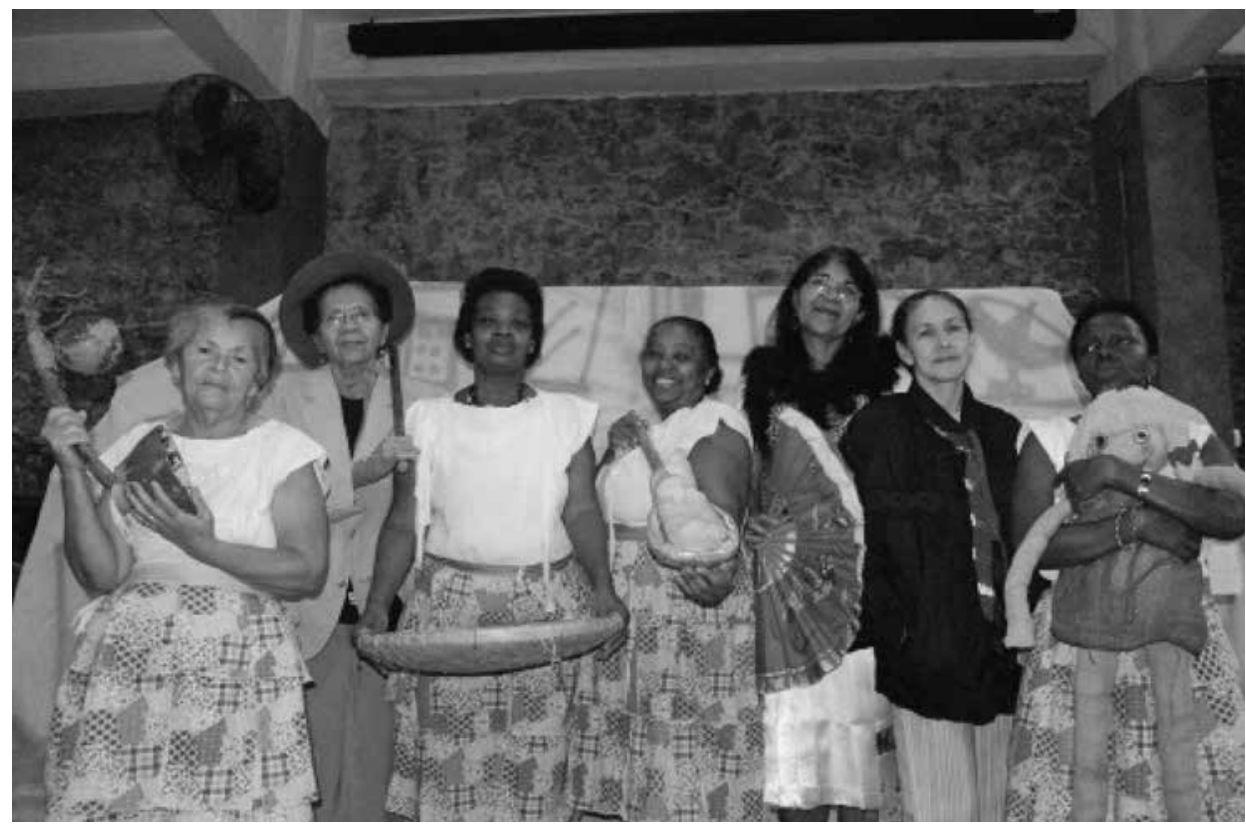

Figura 5. Grupo Marias do Brasil com seu espetáculo Eu Também sou Mulher, em 2010.

Fonte: fotógrafa Noélia Albuquerque.

Iniciada a oficina de formação de grupo, a meta era ter um bom espetáculo teatral: confeccionar figurinos e cenários que acrescentassem a dimensão de suas vidas no palco, cantar e tocar afinadamente suas próprias músicas, decorar o texto, pronunciar as falas de modo claro e sincero. Mas na hora das intervenções do fórum, faltavam argumentos mais definidos, objetivos e aprofundados quanto à discussão dos direitos trabalhistas; como na cena em que a empregada discutia dentro da casa com a patroa sobre seu excesso de tarefas e salário indigno, além de outros direitos profissionais. Aos poucos, foram-se revelando quais as reais opressões vividas por elas, que até então, desejavam somente um trabalho fixo e algum salário para enviar à família no interior do país. 


\section{Teatro Legislativo e formas de criar ações sociais concretas e continuadas}

O silêncio e a submissão apareciam nas técnicas usadas do Teatro do Oprimido, inclusive do Arco-íris do Desejo. Como acreditar em si mesma após anos de invisibilidade? Nestes momentos, nas rodas de conversas iniciais onde o grupo falava dos sonhos e desejos cotidianos, lembrando saudades das famílias: via-se um coletivo com objetivos em comum. Depois os jogos e exercícios amenizavam a tensão do corpo endurecido pelas árduas tarefas diárias. Cada uma contava um fato, uma lembrança; muitas vezes algo adormecido há muito tempo era acordado pelo jogos propostos e a história da peça ia se formando aos olhos e ouvidos de todas.

O grupo foi em busca de parceria com o sindicato, apoiadores para sua causa e, principalmente, em busca de outras trabalhadoras que assistissem às cenas, debatessem as opressões e incorporassem ao projeto.

Embora a categoria de trabalhadores domésticos seja forte, o sindicato tem uma grande luta para conseguir maior adesão junto ao movimento sindical. As Marias do Brasil apoiaram esta mobilização dando oficinas, aplicando técnicas e apresentando espetáculos de Teatro-Forum em eventos e reuniões da categoria, em diferentes espaços públicos. Com jogos, exercícios e técnicas, as tímidas trabalhadoras domésticas, muitas sem saber ler ou escrever, fortaleceram-se para contar suas histórias de vida e montar peças sobre as dificuldades e necessidades de lutar contra as opressões cotidianas das casas dos patrões. Em busca de plenitude da cidadania, as Marias do Brasil aprendem, discutem e divulgam todo o processo legislativo sobre encaminhamentos, votação e resultados obtidos junto aos parlamentares do Congresso Nacional.

O Teatro do Oprimido propõe a visibilização dos personagens e seus conflitos e a exposição de problemas e alternativas possíveis, num processo dialógico e estético. Então o grupo descobre o indivíduo, cada uma das Marias, tem seu próprio estilo. O ritmo frenético e cansativo do trabalho doméstico é reproduzido e diagnosticado nos personagens do espetáculo de Teatro-Forum. A atriz agora percebe a trabalhadora em cena, observa-se e define-lhe ritmos e manejos distintos. Dá-se o primeiro passo: o grupo conhece e convive com os personagens, dando-lhes vida a partir de sua própria vida. 


\section{Conquistas e homenagens pelo trabalho com Teatro do Oprimido}

O Ministério da Cultura entregou o Prêmio de Inclusão da Pessoa Idosa ao grupo em 2007 pelo conjunto de seu trabalho. Em 2011, o grupo foi convidado pelo MST (Movimento dos Trabalhadores Sem Terra) para apresentar seu espetáculo no $1^{\circ}$ Encontro Nacional de Mulheres do Movimento de Atingidos por Barragesn (MAB) para quase duas mil mulheres trabalhadoras da zona rural de todo país com centenas de famílias vítimas de barragens, em Brasília.

Com muita atuação em diversos locais (igrejas, escolas, associação de moradores, grupos de mulheres, sindicatos) houve maior reconhecimento do grupo Marias do Brasil. Em comemoração ao dia internacional de luta contra a violência à Mulher, 25 de novembro de 2014, as Marias do Brasil receberam uma grande homenagem no Salão Nobre da Câmara Municipal do Rio de Janeiro: uma menção honrosa pelos benefícios prestados ao trabalho doméstico junto ao Teatro do Oprimido. Por todos esses anos de existência e luta, vereadores, a presidente do Sindicato das Trabalhadoras Domésticas, a Secretária Municipal dos Direitos da Mulher, amigos e familiares assistiram ao espetáculo "Eu também sou Mulher" e à entrega da homenagem a cada uma das integrantes do grupo. Elas são destaques em programas de televisão e entrevistas de rádios e jornais, revelando a transição entre migrantes e trabalhadoras domésticas para atrizes e sindicalistas atuantes.

Depois de tantas intervenções sociais e políticas, algumas integrantes do gupo decidiram participar mais do Sindicato dos Trabalhadores Domésticos do Rio de Janeiro, onde já eram sócias e voluntárias em atendimentos: atualmente, duas Marias, integrantes do grupo, atuam como diretora e vice-presidente deste sindicato.

Em 2015, o grupo recebeu o Prêmio Ações Locais da Secretaria de Cultura do Estado do Rio de Janeiro para desenvolver um projeto em escolas públicas em cursos noturnos para trabalhadoras domésticas e a formação de um novo grupo e novo espetáculo. Também foram à Patagônia no Festival Internacional Madalenas de Mulheres do Teatro do Oprimido.

As Marias do Brasil, em setembro de 2016, apresentaram seu novo espetáculo para cento e vinte mulheres sindicalistas representantes do Brasil, Costa Rica, México, Chile, Indonésia, Estados Undos e outros países, no palco do XI Congresso Internacional de Trabalhadoras Domésticas no Rio de Janeiro. Este congresso amplia a discussão e a filiação de novas parcerias fortalecedoras da Confederação Latino Americana e Caribenha de Trabalhadoras Domésticas (CONLACTRAHO). 


\section{A continuidade do grupo: projetos futuros já em andamento}

Cada encontro do grupo torna-se reunião para definir rumos e conceitos, ideias e projetos, novos jogos e técnicas e novas lutas. Com a parceria de ONGs vinculadas às questões feministas e trabalhistas do Sindicato dos Trabalhadores Domésticos do Rio de Janeiro e outros estado do Brasil, a nova proposta para a evolução do grupo é:

I. Realização de diversas oficinas de Teatro do Oprimido nas cidades de retorno das Marias para que elas sejam praticantes da metodologia e que esclareçam a lei trabalhista e potencialize a ação e argumentação de crianças, jovens e mulheres trabalhadoras nas zonas rurais.

II. Criação de um Programa de Atenção à Mulher Trabalhadora para formar núcleos em ONGs, associações de moradores e dos sindicatos com oficinas de Teatro do Oprimido que estimulem o conhecimento e aplicabilidade da lei trabalhista voltada para o público feminino.

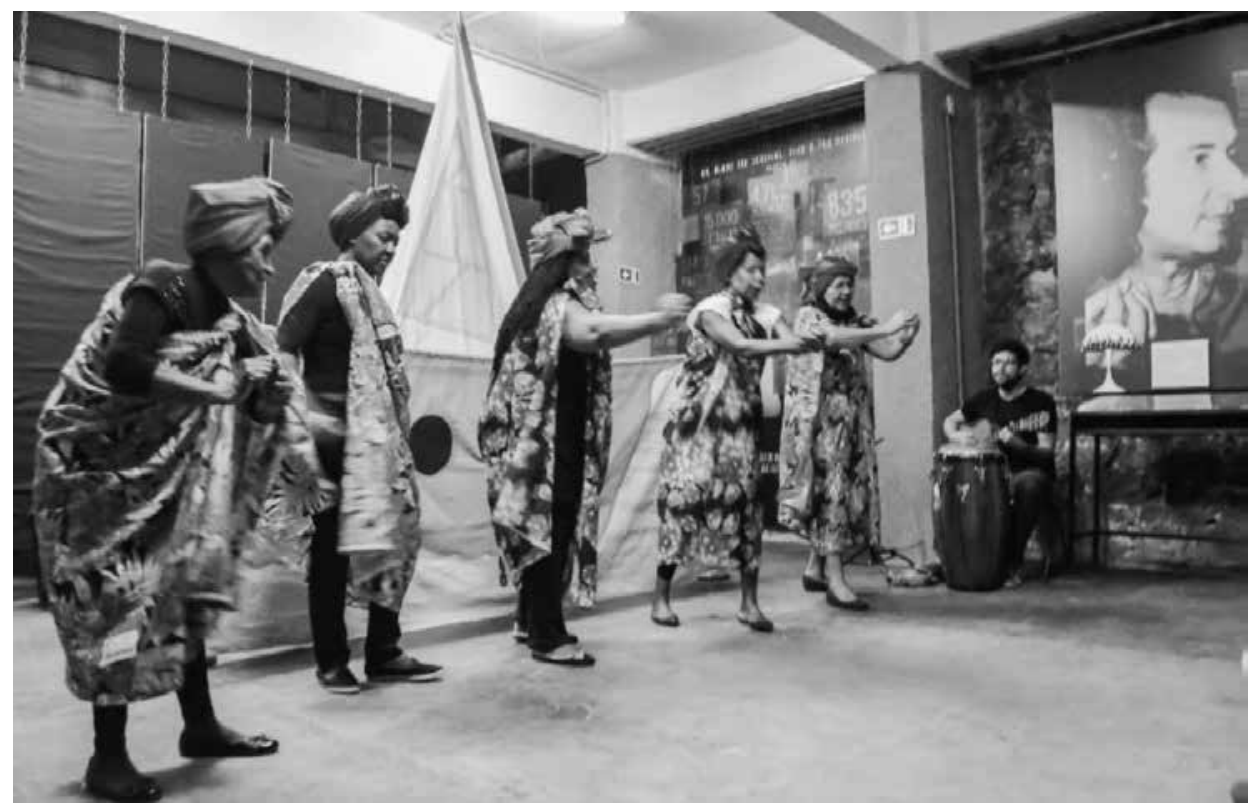

Figura 6. Espetáculo atual "Nós NÃO somos invisíveis", com elenco das Marias do Brasil, na sede do Centro de Teatro do Oprimido, RJ, 2016.

Fonte: fotógrafa Noélia Albuquerque. 
O novo espetáculo, criado a partir do apoio da Secretaria Municipal de Cultura do Rio de Janeiro, chama-se "Nós NÃO somos invisíveis"! e aponta os avanços legislativos desta categoria que enfrenta séculos de opressão física e psicológica; isto ainda dificulta a solução imediata dos muitos problemas a resolver e seguimos com mais uma técnica a ser desenvolvida, ao final do espetáculo, com a participação do público: o Arco íris do Desejo que revela as opressões internalizadas de cada um de nós e potencializa descobertas e alternativas. O método do Teatro do Oprimido é um ato de inquestionável transgressão onde rompem-se os muros entre palco e plateia, espetáculo teatral e vida real, artistas e não-artistas e abrem-se experimentações sensíveis e simbólicas entre arte e cultura.

\section{Considerações finais}

Maria, um nome, um corpo, uma vida. A ressignificação deste nome, sua identidade social, se passam através de uma descoberta corporal na teatralidade proposta pelo método do Teatro do Oprimido. Criaram seus próprios poemas e músicas, as histórias de cada uma aparecem nas cenas dos espetáculos teatrais criados por elas ao longo do tempo. Com as pinturas revelaram seus sonhos e motivaram-se a realizá-los. O teatro impulsiona, o aplauso alegra e as ações legislativas dão legitimidade ao grupo, afinal o Teatro é a soma de todas as linguagens humanas e artísticas.

As Marias do Brasil trazem à tona questionamentos que são destinados ao público convidado: não é simplesmente a busca de soluções aos conflitos discorridos nas cenas, mas a relação dialógica entre palco e plateia, onde o jogo existe porque ambas as partes o aceitam e o usufruem. Alguém que da plateia diga: "Eu tenho uma ideia e vou substituir a Maria neste momento da peça"! Surgem novas possibilidades de intervenção em cena na potência do espectador participativo com atuação tanto artística quanto política.

A metodologia do Teatro do Oprimido aplicada com trabalhadoras domésticas migrantes vindas de regiões secas e destruídas pela ação do homem é eficaz como potencial instrumento para promoção de novos comportamentos. Milhões de mulheres sem opções de trabalho e sobrevivência submetem-se às humilhações e baixo salário como trabalhadora doméstica. $\mathrm{O}$ grupo Marias do Brasil conta suas histórias através do Teatro Forum (técnica interativa onde a plateia substitui o personagem oprimido para mudar as opressões vividas em cena), com músicas e poemas de própria autoria e mostram cenas sobre as péssimas condições de 
vida dos lugares de miséria e seca no interior do Brasil. As leis desta categoria, em tramitação no governo, são mostradas em cena e discutidas com a plateia. $\mathrm{O}$ resultado é a divulgação e apoio às migrantes que saem de sua cidade natal para ganhar a vida no Rio de Janeiro. Dessa maneira plena, compreende-se quando o criador do Teatro do Oprimido sempre dizia: Descobrindo o teatro, o ser se descobre humano (Boal, 1999, p. xx).

Um encontro entre a lei, a arte, os direitos humanos e justiça social para formar caminhos de descobertas, concretas, coletivas e duradouras, envolvidas em ética e solidariedade. As ideias, a vontade de atuar no palco e na vida e as esperanças de melhorar suas realidades continuam... afinal, segundo elas, uma vez e sempre.... Marias do Brasil!

\section{Referências}

Boal, A. (2009) Estética do Oprimido. Rio de Janeiro: Garamond.

Boal, A. (2002) Arco Íris do Desejo. Rio de Janeiro: Civilização Brasileira.

Boal, A. (1999) Jogos para Atores e não Atores. Rio de Janeiro: Civilização Brasileira.

Boal, A. (2003) Teatro como Arte Marcial. Rio de Janeiro: Garamond.

Dados do IBGE (2017) Instituto Brasileiro de Geografia e Estatística.Recuperado de: http://www.ibge.gov.br/home/

Felix, C. (2016) Marias do Brasil, trabalhadoras domésticas e atrizes na luta. Revista Metaxis $\mathrm{n}^{\circ} 8$ (Publicação do Centro de Teatro do Oprimido). Rio de Janeiro.

Freyre, G. (1977) Vida social no Brasil nos meados do século XIX. Instituto Joaquim Nabuco de Pesquisas Sociais. Rio de Janeiro.

Giacomini, S. (1988) Mulher e escrava: Uma Introdução ao Estudo da Mulher Negra no Brasil. Vozes. Rio de Janeiro. 